\title{
Psychiatric disorders and occupational exposure to solvents
}

\author{
F P Labrèche, N M Cherry, J C McDonald
}

\begin{abstract}
Three hundred and eighty one men admitted to hospital for the first time with any psychiatric diagnosis were individually matched for age and year to patients admitted to general hospitals. An occupational history was obtained from $90 \%$ of this study group by telephone interview or mail. Exposure to solvents was assessed by three methods, individual rating of each job recorded, application of an exposure matrix based on job title, and assessment of lifetime job histories of selected case-referent pairs. A sample of individual ratings used in the analysis was compared with ratings made by five experts. The panel values tended to be lower but all six sets of ratings correlated well. There was no increased risk of psychiatric illness among subjects exposed to moderate or greater solvent concentrations for at least 10 years (odds ratio (OR) $1 \cdot 0,90 \%$ confidence interval $(90 \% \mathrm{CI}) \quad 0 \cdot 7-1 \cdot 4$, individual rating; OR $1 \cdot 1$, 90\% CI 0.6-2.0, job title matrix; OR 0.9, $90 \%$ CI $0.5-1 \cdot 7$, lifetime assessments). At higher exposures the risk was increased-although not to a statistically significant degreeespecially for cases with non-psychotic diagnoses (ICD-9 codes 300-316). This negative result, by all three methods of assessment of exposure, contrasted with that from a parallel investigation of cases of organic psychoses and cerebral degeneration.
\end{abstract}

Since the mid-1970s it has been suggested that long term exposure to organic solvents may be associated with an increased risk of neuropsychiatric illness. Several papers (initially from Scandinavia) have reported studies designed to consider the link between exposure to organic solvents and mental

School of Occupational Health, McGill University, Montreal, Quebec, Canada

F P Labrèche, N M Cherry, J C McDonald disorders. Axelson et al ${ }^{12}$ reported an increased risk for all psychiatric diagnoses (odds ratio (OR) 1.8), with an exposure-response trend (ORs 1.3 for less than 30 years of exposure, and 2.3 for 30 years and more). Olsen and Sabroe ${ }^{3}$ found increased relative risks (RRs) ranging from $2 \cdot 1$ for any exposure to $2 \cdot 8$ for indoor exposure among a cohort of carpenters and cabinet makers. In a historical cohort of construction painters, Mikkelsen ${ }^{4}$ found RRs ranging from 1.7 to 3.6 for specific psychiatric diagnostic groups. Studies showing a small but not significantly increased risk were reported from Finland ${ }^{5}$ and from Denmark. ${ }^{6}$ A study from The Netherlands ${ }^{7}$ showed an exposureresponse trend between an index of exposure to solvents in painters and disability pensioning for neuropsychiatric disorders, with no increased overall OR for all disorders. ${ }^{8}$ Two studies focusing on dementia showed no increased risks. ${ }^{910}$ More recently, Gubéran et al ${ }^{11}$ reported a non-significant increase in Switzerland, whereas Brackbill and colleagues ${ }^{12}$ found an increased odds ratio (OR 1.47) for construction painters in the United States. Riise and Moen ${ }^{13}$ reported increased risks for exposed seamen in Norway with rate ratios of 2.7 and $5 \cdot 1$ respectively for captains and mates on tankers.

The studies showing increased risk used exposure indices based essentially on job title, with estimates of exposure within rather than across trades. Studies attempting to assess exposure across occupational groups have shown, at most, insignificant increases in risk $^{6910}$ but it is not clear if this difference reflects inadequacies in assessment of exposure in the negative studies, selective factors in the positive ones, or differences in the neurotoxicity of solvents between exposed occupations.

In view of the need for the widest possible investigation of these questions a two part project was undertaken in Quebec ${ }^{14}$ to evaluate the effects of occupational exposure to solvents, however acquired, on hospital admissions for mental disorder. The first part, reported here, was directed at psychiatric illness in general and the second part ${ }^{15}$ specifically at organic psychoses and cerebral degeneration. 


\section{Methods}

STUDY GROUP

Cases were selected from admission lists of the two psychiatric hospitals in Montreal between April 1981 and March 1985. All men aged 40 to 69 admitted for the first time for five nights or more were identified, for a total of 381 cases. Cases with a final diagnosis of psychosis with origin in childhood (ICD-9, code 299) or of mental retardation of varying severity (ICD-9, codes 317 to 319 ) were excluded. Identification data were retrieved from the hospital charts.

Two series of referents were initially selected to consider different issues: a group of hospital referents to test the main hypothesis and general population referents to verify or otherwise their comparability with the hospital referent series. Only the primary referent group is used in this paper; comparison between the two referent series will be the subject of another report. Two university affiliated general hospitals in Montreal served as the source of hospital referents, individually matched to cases on date of admission (same administrative year) and age at admission ( \pm 2 years). All non-psychiatric diagnoses were eligible except cirrhosis of the liver (possibly associated with high intake of alcohol) and admissions for elective surgery or injuries after an accident (absence of corresponding illness in psychiatric patients); the referents' admissions did not have to be the first for that cause. A previous psychiatric admission caused rejection of the referent. Only cases and referents resident in Quebec or the adjacent provinces of Ontario and New Brunswick at time of tracing were studied.

\section{DATA COLLECTION AND HANDLING}

Data collection and handling were conducted by research assistants ignorant of the subjects' case or referent state. An introductory letter was first sent explaining the study, followed by a telephone interview about a week later. A structured questionnaire was used to obtain information on demographic variables (date and place of birth, father's occupation, schooling, etc), occupational history (job title,

\section{Table 1 Level of participation}

\begin{tabular}{lrr}
\hline & Cases & $\begin{array}{r}\text { Hospital } \\
\text { referents }\end{array}$ \\
\hline Information from respondent or family member: & \\
Complete questionnaires & $287(75 \%)$ & $322(84 \%)$ \\
Incomplete questionnaires & $42(11 \%)$ & $37(10 \%)$ \\
Information from other sources: & & \\
Untraced: & $17(5 \%)$ & $6(2 \%)$ \\
$\quad$ Some information & $12(3 \%)$ & $3(1 \%)$ \\
$\quad$ No information & $19(5 \%)$ & $12(3 \%)$ \\
Uncooperative: & $3(1 \%)$ & $1(0 \%)$ \\
$\quad$ Some information & $1(0 \%)$ & $0(0 \%)$ \\
$\quad$ No information & $381(100 \%)$ & $381(100 \%)$ \\
No informant available & & \\
Total & &
\end{tabular}

economic activity of the company, years in each job, description of activities, and checklist of exposure to solvents, pesticides, and metals), hobbies (entailing exposure to organic solvents), personal habits (smoking, alcohol intake), and medical history. Reluctant subjects were sent a short letter asking about their main jobs and, if then willing, a brief questionnaire on their work history. If the subject had died or was unable to communicate, a family member or friend was interviewed. For subjects in hospital but likely to be well enough to answer a questionnaire after discharge, the interviewer telephoned after the return home.

\section{RESPONSE RATES}

In $86 \%$ of cases and $94 \%$ of referents job information was obtained directly from the subject or a close proxy respondent (table 1 ). Limited information was obtained from hospital records for 36 cases and 18 hospital referents and no information for 16 cases and four hospital referents. The proportion of surrogate respondents was similar for cases (30\%) and hospital referents $(32 \%)$.

\section{EXPOSURE ASSESSMENT}

Exposure to solvents was assessed in three ways, always without knowledge of the subject's case or referent state. Firstly, each job was reviewed by one of us (FL), and an estimate made of intensity of exposure. This assessment was basically on a scale of 0 to 3, where 0 signified no exposure (or not more than that experienced by an average citizen); 1, light exposure (a level not thought biologically important); 2 , moderate exposure (levels that might need to be monitored-probably from 30 to $50 \%$ of the threshold limit value (TLV)); and 3, significant exposures (a level considered undesirable-probably over $50 \%$ of the TLV). To facilitate classification (see later) the scale was extended to 10 points, analogous to that developed by Liddell to classify chest radiographs. ${ }^{1617}$ The score was recorded as the intensity attributed, followed by an oblique and then the alternative intensity seriously considered, giving a logical sequence of $0 / 0,0 / 1,1 / 0,1 / 1,1 / 2,2 / 1,2 / 2$, $2 / 3,3 / 2$ and $3 / 3$. The percentage of the work week entailing exposure was also estimated for each job. This rating took account of all information provided by the respondent about the task carried out and the exposure reported. All periods of employment for all subjects were assessed individually: this method is referred to as "individual rating". The procedure, although sensitive, was subjective and therefore not easily repeatable in future studies.

A second method entailed the construction of an exposure matrix based on job title with help from a team of three experienced physicians or hygienists. The three experts working independently assessed the probable level of occupational exposure in job 
categories identified from four figure codes used for the 1986 Canadian census. Job titles were identified by preliminary screening: only those that had been rated by FL on at least $10 \%$ of occasions at level 1 or more were included. Of the 131 job titles thus selected the same exposure level, using the four point scale described above, was recorded by all three assessors in $63(48 \%)$, and by two of the three in a further $61(47 \%)$. The remaining seven jobs, for which there was no concordance, were assigned the median of the three ratings. All jobs that failed the preliminary screen were considered as unexposed. Overall, 35 job titles were assessed at level 1, 11 at level 2, and only five (painters in construction; printing press operators; other printing operatives; launderers and dry cleaners; workers in marine craft fabrication) at level 3. The matrix of exposure and four figure occupation codes were then merged with the job history file. This second method of assessment of exposure was essentially objective and thus usable in future studies; however, it did not make use of information on individual differences of exposure between jobs within the same broad category. This method is referred to as the "job title matrix".

Thirdly, the same three experts assessed lifetime job histories of a selected sample of case and referent pairs to judge whether either subject had received important exposures thought capable of causing organic damage and which had been the more heavily exposed. This approach-again subjective-was restricted to 96 case and referent pairs in whom either or both had been rated by FL to have been exposed at level 2 or greater for at least 10 years. This method is referred to as the "lifetime assessment".

\section{CONFOUNDING FACTORS}

Intake of alcohol was documented as a continuous variable and used as a categorical variable contrasting no alcohol with an intake of less than 14 units of alcohol per week and 14 units and above; one unit was equal to $350 \mathrm{ml}$ beer, $120 \mathrm{ml}$ wine, or $45 \mathrm{ml}$ spirits. Exposure to lead and pesticides was recorded for each job, but only whether or never exposed was used in the analysis. Socioeconomic state during childhood was considered low for subjects whose father had a score of less than 35 on the Blishen scale..$^{18}$ Immigrant state was determined from whether the subject was born in Canada or not. Finally, exposure to solvents outside work was roughly estimated from whether the subject had a hobby that entailed the use of solvents. Head injury, stroke, and age at leaving school, considered as confounders in the parallel study, ${ }^{15}$ did not vary between case and referent series in the study reported here. ${ }^{19}$

\section{RELIABILITY STUDY}

Job descriptions provided by study subjects were presented to each of two panels, one in Montreal (two industrial hygienists and FL) and one in London (three international experts). The sample, weighted with exposed jobs to increase the likelihood of disagreement, comprised $1.5 \%$ of jobs rated as not exposed by FL and $15 \%$ of jobs rated as $1 / 0$ or above. Each rater evaluated 312 job descriptions with the 10 point scale. Also, FL rated 156 jobs in two consecutive days to evaluate intrarater reliability.

\section{STATISTICAL ANALYSIS \\ Reliability study}

The percentage of exact agreement between FL and the other raters on two occasions was calculated as a proportion of identical ratings on the four point scale. The extent and direction of disagreement were calculated by adding the number of ratings that were lower (underestimations) or higher (overestimations) than other ratings. Spearman's rank correlation coefficients were computed, on the 10 point scale, between raters. The kappa statistic was not used in these comparisons because of difficulties in interpretation with more than two raters and two classification categories. $^{20}$

\section{Solvent exposure}

Except for some descriptive statistics, all analyses were in matched pairs; contingency tables were set up to calculate odds ratios with and without stratification for possible confounders. Mathematical modelling provided adjusted estimates by logistic regression. Confidence intervals were calculated at $90 \%$ because our hypothesis was one sided.

Although our prior hypothesis was concerned only with exposures at moderate levels (level 2) and above for 10 years or more, we also considered exposures at level 3 because FL had tended to overestimate intensity of exposure compared with the European panel.

\section{Results}

\section{RELIABILITY STUDY}

Intrarater agreement (FL) was high with $81 \%$ of 156 jobs being given the same rating on the four point scale on two different occasions; disagreements were equally distributed between under and overestimations. The correlation between ratings on the 10 point scale was 0.96 . Interrater exact agreement on the four point scale ranged from $49 \%$ to $60 \%$ (table 2). In comparison with each of the experts on the London panel, FL tended to have overestimated exposure. This was less evident with the Montreal panel who were more familiar with local conditions. Correlations between the ratings of FL (rater 1 in table 3) and the other raters lay between 0.68 and 0.81 . Inspection of coefficients for all raters, the lowest being 0.63 , suggests that there was high agreement in the ranking, by experts from many 
Table 2 Agreement between the individual ratings and those of the expert panels based on four point scale $(n=312)$

\begin{tabular}{|c|c|c|c|c|c|}
\hline & \multicolumn{2}{|c|}{ Montreal panel } & \multicolumn{3}{|c|}{ London panel } \\
\hline & $\begin{array}{l}F L v \\
\text { rater } 2\end{array}$ & $\begin{array}{l}F L v \\
\text { rater } 3\end{array}$ & $\begin{array}{l}F L v \\
\text { rater } 4\end{array}$ & $\begin{array}{l}F L v \\
\text { rater } 5\end{array}$ & $\begin{array}{l}F L v \\
\text { rater } 6\end{array}$ \\
\hline Exact agreement & $179(57 \%)$ & $165(53 \%)$ & $153(49 \%)$ & $186(60 \%)$ & $176(56 \%)$ \\
\hline $\begin{array}{l}\text { Disagreement: } \\
\text { Underestimation } \\
\text { Overestimation }\end{array}$ & $\begin{array}{l}44(14 \%) \\
89(29 \%)\end{array}$ & $\begin{array}{l}76(24 \%) \\
71(23 \%)\end{array}$ & $\begin{array}{c}17(5 \%) \\
141(45 \%)\end{array}$ & $\begin{array}{c}21(7 \%) \\
105(34 \%)\end{array}$ & $\begin{array}{r}30(10 \%) \\
106(34 \%)\end{array}$ \\
\hline
\end{tabular}

Table 3 Spearman's rank correlation coefficients ${ }^{\star}$ between all the raters based on 10 point scale $(n=312)$

\begin{tabular}{lllll}
\hline & Rater 1 & Rater 2 & Rater 3 & Rater 4 \\
\hline Rater 2 & 0.80 & 1 & & \\
Rater 3 & 0.68 & 0.74 & 1 & \\
Rater 4 & 0.81 & 0.76 & 0.67 & 1 \\
Rater 5 & 0.80 & 0.75 & 0.72 & 0.82 \\
Rater 6 & 0.78 & 0.72 & 0.63 & 0.75 \\
\hline
\end{tabular}

^Correlation coefficients corrected for ties; all significant at $\mathrm{p}<0.001$.

Table 4 Case and referent diagnoses

\begin{tabular}{|c|c|c|c|}
\hline$I C D-9$ & Diagnosis & $\%$ & No \\
\hline $\begin{array}{l}290-294 \\
295-298 \\
300-312\end{array}$ & $\begin{array}{l}\text { Organic psychotic conditions } \\
\text { Other psychoses } \\
\text { Non-psychotic conditions }\end{array}$ & $\begin{array}{r}11 \\
33 \\
56 \\
100\end{array}$ & $\begin{array}{r}43 \\
125 \\
213 \\
381\end{array}$ \\
\hline $\begin{array}{l}140-239 \\
390-459 \\
460-519 \\
520-579 \\
580-611 \\
\star\end{array}$ & $\begin{array}{l}\text { Neoplasms } \\
\text { Defer } \\
\text { Diseases of the circulatory system } \\
\text { Diseases of the respiratory system } \\
\text { Diseases of the digestive system } \\
\text { Diseases of the genito-urinary system } \\
\text { Other diagnoses }\end{array}$ & $\begin{array}{r}14 \\
34 \\
7 \\
16 \\
7 \\
21 \\
100\end{array}$ & $\begin{array}{r}55 \\
130 \\
26 \\
62 \\
27 \\
81 \\
381\end{array}$ \\
\hline
\end{tabular}

^Including ill defined conditions (ICD-9 codes 780-799) and factors influencing health status and contact with health services (ICD-9 ' $V$ ' codes).

backgrounds, of likely exposures to solvents across a broad spectrum of occupations.

\section{EXPOSURE TO SOLVENTS}

Table 4 presents the distribution of cases and hospital referents by diagnostic group. Slightly fewer than half the diagnoses were of psychoses. The distribution of diagnoses in the referent group was in line with the morbidity pattern of the Quebec male population..$^{21}$ The only apparent difference in the distribution of potential confounders was a larger proportion of immigrants among cases compared with hospital referents (table 5). Close matching on age was achieved: both cases and hospital referents had the same average age (54.1) on admission. A substantial difference in average duration of stay was expected and found: cases spent 43.5 days in hospital whereas hospital referents were discharged after 16.6 days.
Table 6 shows the unadjusted odds ratios for exposure at moderate solvent levels (level 2) for the main diagnostic categories. The odds ratios showed no apparent trend, all lying around 1 . The job title matrix method gave slightly higher odds ratios than the individual ratings.

Adjustment of the combined effects of possible confounders was made by logistic regression on pairs with complete questionnaires based on individual ratings only (table 7). The OR for all diagnoses increased slightly from 1.0 to $1 \cdot 1$. Within cases with a psychotic diagnosis the odds ratio was essentially unchanged after adjustment for confounders. The odds ratio for non-psychotic cases increased from 1.1 to 1.5 after regression with confounders.

Among the confounders, only immigrant state reached significance; cases with psychotic and nonpsychotic diagnoses were born outside Canada more often than referents. Of the other factors, only 
Table 5 Distribution of potential confounders

\begin{tabular}{lll}
\hline & Cases & Referents \\
\hline Long questionnaire completed & 287 & 322 \\
Alcohol ever > 14 units/week & $34 \%(277)$ & $33 \%(318)$ \\
Lead ever (at work) & $14 \%(286)$ & $17 \%(322)$ \\
Pesticides ever (at work) & $5 \%(286)$ & $5 \%(322)$ \\
Immigrant to Canada & $16 \%(286)$ & $7 \%(322)$ \\
Father's job "low status" & $61 \%(259)$ & $60 \%(301)$
\end{tabular}

Number of questionnaires on which the information was recorded are shown in parentheses.

exposure to lead among the psychotic cases and high alcohol intake among the non-psychotic cases approached statistical significance.

When the three London experts were asked to judge which of the cases and referents in 96 pairs had been exposed during their lifetime to solvent intensities likely to be biologically important, 40 cases or referents were identified by at least two of them. Seventeen pairs contained a case but not a referent, 19 a referent but not a case, and two pairs had both case and referent importantly exposed. When the criterion was tightened to require that all three experts agreed that a subject had been exposed in this way, 23 pairs were identified, 11 with the case and 12 with the referent exposed. Odds ratios from these data were $0.9(90 \% \mathrm{CI} 0.5-1.7$; two experts agreed) and $1.1(90 \%$ CI $0.5-2.6$; three experts agreed). These were in line with odds ratios calculated from the individual or job matrix ratings.

\section{Discussion}

There was clearly no evidence in our study that admission to hospital for a psychiatric illness was related to occupational exposure to solvents at moderate or even high intensity for 10 years or more. The association between non-psychotic diagnoses and exposure at level 3 was less clearly negative but not convincingly so; the odds ratio based on individual ratings was $1.5(90 \% \mathrm{CI} 0.6-3.9)$ and on job title matrix $1 \cdot 3(90 \% \mathrm{CI} 0 \cdot 2-9 \cdot 0)$. With psychotic diagnoses, the odds ratios were below 1 by both assessment methods. The association of an alcohol related diagnosis (ICD-9 codes 291 and 303), of interest because of findings in our parallel study, ${ }^{15}$ was explored first for all and then for psychotic and nonpsychotic diagnoses, but had no clear effect. Odds ratios were all around 1.0 by individual ratings, and varied from 0.4 to 2.0 by job title matrix, probably due to small numbers in some sub-categories.

Possible reasons for the apparent difference between these findings and the early positive findings from Scandinavia must be considered. Our reliability study showed that FL's exposure ratings, although similar to those of the two other Quebec experts, were higher than those of the international panel. The correlation for all six raters was high, however, and the use of job exposure matrix ratings and evaluation by the international panel of case-referent pairs were equally negative. It is unlikely, therefore, that exposure assessment itself was responsible although it might again be noted that the Scandinavian studies

Table 6 Odds ratios for solvent exposure by diagnosis: general hospital referents

\begin{tabular}{|c|c|c|c|c|c|c|}
\hline \multirow[b]{2}{*}{ Diagnosis } & \multicolumn{3}{|c|}{ Individual ratings } & \multicolumn{3}{|c|}{ Job title matrix } \\
\hline & $\begin{array}{l}\text { Number } \\
\text { of pairs }\end{array}$ & Discordant & $\begin{array}{l}\text { OR } \\
(90 \% C I)\end{array}$ & $\begin{array}{l}\text { Number } \\
\text { of pairs }\end{array}$ & Discordant & $\begin{array}{l}\text { OR } \\
(90 \% C I)\end{array}$ \\
\hline $\begin{array}{l}\text { Psychotic diseases } \\
\text { Non-psychotic diseases }\end{array}$ & $\begin{array}{l}149 \\
202\end{array}$ & $\begin{array}{l}19 / 22 \\
26 / 24\end{array}$ & $\begin{array}{l}0.9(0.5-1.6) \\
1.1(0.6-1.9)\end{array}$ & $\begin{array}{l}152 \\
203\end{array}$ & $\begin{array}{l}13 / 10 \\
11 / 11\end{array}$ & $\begin{array}{l}1.3(0.6-3 \cdot 1) \\
1.0(0.4-2 \cdot 4)\end{array}$ \\
\hline Total & 351 & $45 / 46$ & $1.0(0.7-1.4)$ & 355 & $24 / 21$ & $1 \cdot 1(0 \cdot 6-2 \cdot 0)$ \\
\hline
\end{tabular}

Table 7 Solvent exposure and confounding factors: logistic regression analyses

\begin{tabular}{|c|c|c|c|}
\hline Variables & $\begin{array}{l}\text { All diagnoses } \\
\text { OR } \\
(90 \% C I)\end{array}$ & $\begin{array}{l}\text { Psychotic diseases } \\
\text { OR } \\
(90 \% \mathrm{CI})\end{array}$ & $\begin{array}{l}\text { Non-psychotic diseases } \\
\text { OR } \\
(90 \% \text { CI) }\end{array}$ \\
\hline $\begin{array}{l}\text { Occupational solvent exposure } \\
\text { Lead exposure } \\
\text { Pesticide exposure } \\
\text { Non-occupational solvent exposure } \\
\text { Immigrant state } \\
\text { Alcohol intake <14 units/week } \\
\text { Alcohol intake } \geqslant 14 \text { units/week } \\
\text { Number of pairs }\end{array}$ & $\begin{array}{l}1 \cdot 1(0 \cdot 7-1 \cdot 8) \\
1.0(0 \cdot 6-1 \cdot 5) \\
0 \cdot 8(0 \cdot 4-1 \cdot 6) \\
0 \cdot 8(0 \cdot 6-1 \cdot 1) \\
2 \cdot 7(1 \cdot 5-4 \cdot 7) \\
1 \cdot 2(0 \cdot 8-1 \cdot 9) \\
1.2(0 \cdot 8-1 \cdot 7) \\
227\end{array}$ & $\begin{array}{l}0.9(0 \cdot 5-1 \cdot 7) \\
2 \cdot 0(1 \cdot 0-4 \cdot 1) \\
0 \cdot 5(0 \cdot 2-1 \cdot 3) \\
1 \cdot 0(0 \cdot 6-1 \cdot 6) \\
3 \cdot 2(1 \cdot 4-7 \cdot 6) \\
1 \cdot 3(0 \cdot 7-2 \cdot 4) \\
0 \cdot 7(0 \cdot 4-1 \cdot 3) \\
100\end{array}$ & $\begin{array}{l}1.5(0 \cdot 8-3 \cdot 0) \\
0 \cdot 6(0 \cdot 3-1 \cdot 2) \\
1.2(0 \cdot 5-3 \cdot 2) \\
0 \cdot 6(0 \cdot 4-1 \cdot 0) \\
3 \cdot 0(1 \cdot 3-6 \cdot 8) \\
1.3(0 \cdot 7-2 \cdot 3) \\
1.7(1 \cdot 0-2 \cdot 9) \\
127\end{array}$ \\
\hline
\end{tabular}


mostly entailed comparison within specific industries whereas ours was across industries.

A more probable explanation of differing findings may lie in the type of mental disorder selected for study. Comparatively few of the subjects in the Scandinavian investigations are likely to have required hospital admission whereas in our study it was the prerequisite. The effects of long term exposure to solvents in fairly benign behavioural disorders and severe psychiatric diseases may be quite different. Even in the second, our results suggest that such exposure has little general effect and was only of major importance in patients with organic brain damage who also had evidence of high intake of alcohol. ${ }^{15}$ In the present study, only about $11 \%$ of psychiatric admissions were in this category and fewer still had evident alcoholism-too few, having regard for sampling variation, to have affected the overall result.

There remains, of course, the limitation of all case and referent comparisons. An apparent difference, or lack of it, may reflect the characteristics of either series in terms of the exposure of interest or of selective and perhaps unrecognised confounders. International comparisons between studies of mental and behavioural disorders where social, economic, and cultural factors are of major importance must be made with caution.

This work was supported by a research grant from the Institut de recherche en santé et en sécurité du travail du Québec (IRSST). One of us (FL) was in receipt of post graduate scholarships from the IRSST and from McGill University. Members of the expert panels were: (Montreal) D Bégin and J Lavoie; (London) O Axelson, R Riala, and H A Waldron. Questionnaires were administered by Donna Amyot.

Requests for reprints to: Professor N M Cherry, Centre for Occupational Health, University of Manchester, Stopford Building, Oxford Rd, Manchester M13 9PT.

1 Axelson O, Hane M, Hogstedt C. A case-referent study on neuropsychiatric disorders among workers exposed to solvents. Scand J Work Environ Health 1976;2:14-20.
2 Axelson $\mathrm{O}$. Epidemiology of solvent-related neuropsychiatric disorders. In: Cherry NM, Waldron HA, eds. The neuropsychological effects of solvent exposure. Havant: The Colt Foundation, 1983:85-99.

3 Olsen J, Sabroe S. A case-reference study of neuropsychiatric disorders among workers exposed to solvents in the Danish wood and furniture industry. Scand J Soc Med 1980; (suppl 16):44-9.

4 Mikkelsen S. A cohort study of disability pension and death among painters with special regard to disabling presenile dementia as an occupational disease. Scand J Soc Med 1980;(suppl 16):34-43.

5 Lindström K, Riihimäki H, Hänninen K. Occupational solvent exposure and neuropsychiatric disorders. Scand J Work Environ Health 1984;10:321-3.

6 Rasmussen H, Olsen J, Lauritsen J. Risk of encephalopathia among retired solvent-exposed workers. J Occup Med 1985;27:561-6.

7 van Vliet C, Swaen GMH, Slangen JJM, et al. The organic solvent syndrome. A comparison of cases with neuropsychiatric disorders among painters and construction workers. Int Arch Occup Environ Health 1987;59:493-501.

8 van Vliet C, Swaen GMH, Volovics A, et al. Exposure-outcome relationships between organic solvent exposure and neuropsychiatric disorders: results from a Dutch case-control study. Am J Ind Med 1989;16:707-18.

9 O'Flynn RR, Monkman SM, Waldron HA. Organic solvents and pre-senile dementia: a case referent study using death certificates. Br J Ind Med 1987;44:259-62.

10 Shalat SL, Seltzer B, Baker EL. Occupational risk factors and Alzheimer's disease; a case-control study. J Occup Med 1988;30:934-6.

11 Gubéran E, Usel M, Raymond L, Tissot R, Sweetnam PM. Disability, mortality, and incidence of cancer among Geneva painters and electricians: a historical prospective study. $\mathrm{Br} J$ Ind Med 1989;46:16-23.

12 Brackbill RM, Maizlish N, Fischbach T. Risk of neuropsychiatric disability among painters in the United States. Scand $J$ Work Environ Health 1990;16:182-8.

13 Riise T, Moen BE. A nested case-control study of disability pension among seamen, with special reference to neuropsychiatric disorders and exposure to solvents. Neuroepidemiology 1990;9:88-94.

14 Cherry NM, Labrèche F, McDonald JC. Dementia and solvent exposure at work. In: Hogstedt C and Reuterwall C (eds). Progress in occupational epidemiology. Excerpta Medica, International congress series 1988;809:247-8.

15 Cherry NM, Labrèche FP, McDonald JC. Organic brain damage and occupational solvent exposure. $\mathrm{Br} J$ Ind $\mathrm{Med}$ 1992;49:776-81.

16 International Labour Office. Guidelines for the use of ILO International Classification of radiographs of pneumoconiosis. Geneva: ILO, 1980. (Occupational Safety and Health series No 22.)

17 Liddell FDK. An experiment in film reading. $\mathrm{Br} J$ Ind $\mathrm{Med}$ 1963;20:300-12.

18 Blishen BR, McRoberts HA. A revised socioeconomic index for occupations in Canada. Canadian Review of Sociology and Anthropology 1976;13:71-9.

19 Labrèche FP. Occupational solvent exposure and mental disorders. (PhD thesis) Montreal: McGill University, 1989.

20 Maclure M, Willett WC. Misinterpretation and misuse of the Kappa statistic. Am J Epidemiol 1987;126:161-9.

21 Statistics Canada. Hospital morbidity 1981-1982 and 1982-1983. Ottawa: Minister of Supply and Services, 1986. (Catalogue No 82-206.)

Accepted 9 March 1992 